\title{
Image Processing Based Plant Disease Detection and Automated Treatment
}

\author{
Mr. P. Senthil Kumar ${ }^{1}$, V. Yoganivetha ${ }^{2}$, R. Sindhuja Rakavi ${ }^{3}$, S.Thilagavathi ${ }^{4}$, N. Vigneshwaran ${ }^{5}$ \\ Assistant Professor, Department of Electronics and Communication Engineering, Velalar College of Engineering and \\ Technology, Erode, India ${ }^{1}$
}

UG Student, Department of Electronics and Communication Engineering, Velalar College of Engineering and

Technology, Erode, India ${ }^{2,3,4,5}$

\begin{abstract}
The protection of plants and crops in the farming fields is extremely important, because they form the basis for survival of humans every day. Such plants are often subject to various factors like viral, bacterial or fungal diseases that cause degradation and even the death of the plants, by gradually deteriorating them when they are healthy, thus decreasing the crop yield, and also makes them unfit for consumption by humans. In order to tackle this issue and lend a helping hand to the farmers, this paper introduces a system which will detect if a plant is affected by a disease or not, with a greater accuracy, by processing the captured appropriate plant images and spray the medicine automatically if it is found diseased. In addition to this, the system can also check if enough water is held for plants using water sensor, and pump water to the plants automatically, in the farming land. With this system, time can be saved to the maximum for farmers, since it promotes automation in farming. Also, this will be of help in a number of farming applications like in organic farming.
\end{abstract}

Keywords: Plant Leaf images, MATLAB, Arduino Uno, Image processing, Automation, Water sensor

\section{INTRODUCTION}

The fact that the process of growing and harvesting crops and plants requires a lot of measures to be taken in the agricultural fields is inevitable, beginning from seeding of crops in fields to harvesting of the same, as a result of restless hardship and efforts the farmers would take in bringing them up, by often making sure that the crops are not affected by any kind of destroying factors, especially by disease-causing agents like viruses, bacteria, etc. For taking care of the health of crops and plants, the farmers have to spend most of their time in the field for watering and fertilizing them manually, which would definitely exhaust them of energy for the whole day. In this place, the introduction of a system which can perform the task of identifying diseased plants and automatically treat them with either appropriate medicine or fertilizer will be of greater help than any other alternatives to the farmers. The plant or a crop is tested using Image processing with the help of MATLAB software to see if the plant is affected by a disease or not, and if found diseased, the system makes the sprinkler automatically spray the fertilizer or medicine to the similarly affected plants. Also, the system does an additional task of measuring the water level to check if the furrows in the field hold enough water required for the plants, and if not, it turns on the pipe for water to flow. This system, in this way, will save the time for farmers to a great extent, as the tasks of monitoring and treating the crops and plants in the field are automated.

\section{LITERATURE SURVEY}

Prakash et al. (2017) investigated how image processing can be implemented in the agricultural field to detect weed areas in the image taken from the field, using MATLAB software. Several images of various disease affected leaves are given as input to the system, since the images taken might vary, if there were two or kinds of weeds existing in the field. Then accordingly the threshold value of the edge frequency is reduced such that it is less than the minimum threshold value.

Sankaran S. et al. (2010) studied and reviewed various techniques existing for plant disease detection, realizing the inevitable need for a proper crop management system for early information on crop health and disease detection, facilitating the control of diseases through proper strategies. They have studied and compared the benefits and limitations of several potential disease detection methods. 


\section{PROPOSED METHOD}

The Proposed system includes detection of plant leaf, which is diseased and enabling or disabling of medicines or fertilizers automatically. The motivation of this system is that,

1. Plant diseases cause major losses economically and also in production wise in agriculture.

2. A need to build a system that does the overall task of protecting plants from various disease causing factors and take necessary actions.

The proposed system not only checks if the plant is diseased or not, but also automatically sprays the appropriate medicine or fertilizer saving time for farmers. The image of a plant leaf is first captured and system directly stores that image as the reference image. Then, when capturing other images, the comparison is made and decision is taken if the considered plant is diseased or not. Once it is made sure that the plant is affected by a disease, the system turns on the sprinkler to treat the affected plant. Meanwhile, the system can also monitor if there is enough water in the furrows in the field for irrigating the plants, using water sensor.

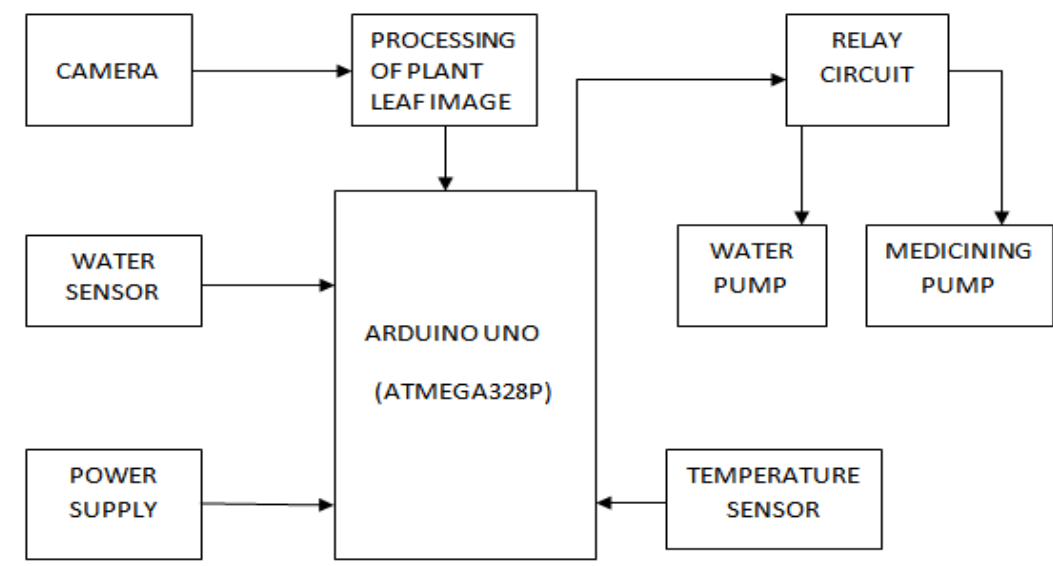

Figure 1 Block Diagram

\section{A. Arduino Uno}

Arduino Uno is a microcontroller board, based on ATmega8/168/328 UNO R3 major in ATmega328. It contains everything needed to support the microcontroller; simply connect it to a computer with a USB cable or power it with an AC-to-DC adapter or battery to get started. Instead, it features the Atmega16U2 (Atmega8U2 up to version R2) programmed as a USB-to-serial converter. The Arduino Uno can be powered via the USB connection or with an external power supply. The power source is selected automatically. External (non-USB) power can come either from an AC-to-DC adapter (wall-wart) or battery.

B. Dual Relay Circuit Module

A relay is an electrically operated switch. Many relays are use an electromagnet to mechanically operate a switch, but other operating principles are also used. Relays are used where it is necessary to control a circuit by a separate low power signal, or where several circuits must be controlled by one signal. The dual relay driver circuit is used to turn ON or OFF the medicining pump whenever the plant is detected with a disease. Also, the water pump will be turned on to irrigate the plants when it finds that water present in the furrows is not enough.

\section{Water Sensor}

Water level detection sensor works on the principle of conduction through the water. It can be used for water level detection, rainfall detection, water leakage detection, etc. The sensor has been divided into two parts, a sensing module also known as a brick and a circuit module. In analog mode, larger the amount of liquid, more will be the voltage produced at the output and hence, the same is observed and can be used to detect the level of water in an overhead tank by either using multiple sensors or by increasing the length of tracks. This item has low power consumption, and high sensitivity which are the biggest characteristics of this module.

\section{Camera}

The camera plays the essential role of capturing the plant leaf images, in order to process those images with the help of image processing tool in MATLAB. The camera has to be good enough to capture clear image of the desired object. 
Vol. 8, Issue 2, February 2019

\section{E. Temperature Sensor}

Temperature sensor is used to identify the temperature of the surrounding environment in which the sensor is doing its task. The circuit of a temperature sensor is possible with a Thermistor. A thermistor is a resistor which increases or decreases its resistance depending on the temperature in the surroundings or the circuit. There are two types of thermistors as, Negative temperature Coefficient (NTC) and Positive Temperature Coefficient (PTC) thermistors. There is also a cost effective IC called LM35 that does the task of sensing the surrounding temperature.

\section{F. $\quad$ Image Processing Of Plant Leaf Images Using MATLAB}

MATLAB is a numerical computing environment and programming language, maintined by the MathWorks. MATLAB allows easy matri manipulation, plotting of functions and data, implementation of algorithms, creation of user interfaces, and interfacing with programs in other languages. It is now also used in education, in particular the teaching of linear algebra and numerical analysis, and is popular amongst scientists involved with image processing. The plant images captured with a real-time camera are first scanned thoroughly for finding any difference with the reference image already stored. After the interpretation of the images captured, the system evaluates the result whether the plant is affected or not. These tasks of processing the plant images are carried out effectively by using MATLAB image processing tool.

The principle of work is by making geometrically align the two processed images- the reference and sensed images. The present differences between images are introduced due to different imaging conditions. Image registration can be considered as a crucial step in all image analysis tasks in which the final information is gained from the combination of various data sources like in image fusion, change detection, and multi channel image restoration. The image captured is taken in its RGB format and compared further with the already available reference image to find if there is any variation in the colour and other parameters, and infer whether the plant leaf is affected by a disease or not. K-means clustering method is one of those image processing techniques used for the segmentation of the images captured. Segmentation partitions the image in to meaningful parts for better analysis and understanding of the image. Thresholding and region growing are two basic approaches of segmentation. Thresholding is simplest where gray image can be partitioned based on threshold value.

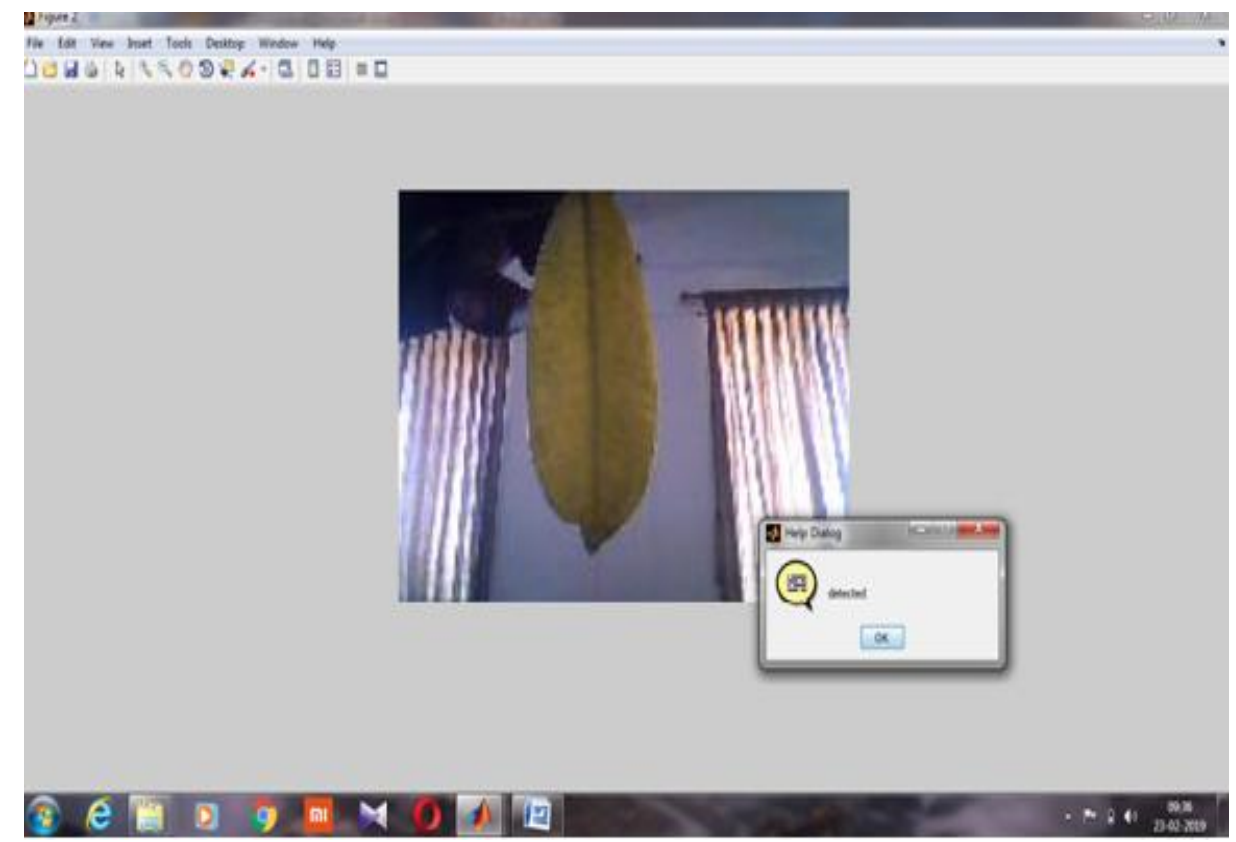

Figure 2 Detection of Infected leaf

\section{CONCLUSION}

Thus a system which will be helpful for farming, through cost effective automation has been discussed in this paper. This kind of methodology is very much necessary, not only for farming, but also for other applications like, food grading, military use, etc. Since image processing is becoming one of the most followed techniques in detecting complex and complicated substances, use of such technique in this system with a better accuracy will be helpful to the farmers in the field. 


\section{IJARCCE}

Vol. 8, Issue 2, February 2019

\section{REFERENCES}

[1]. Prakash, K., Saravanamoorthi, P., Sathishkumar, R., \& Parimala, M., 2017 'A Study of Image processing in Agriculture', International Journal of Advanced Networking and Applications, Vol. 09, Issue 01, pp. 3311-3315.

[2]. Sankaran, S., Mishra, A., Ehsani, R., \& Davis, C., 2010 'A Review of Advanced Techniques for detecting plant diseases', Elsevier, Computers and Electronics in Agriculture, Vol. 72, Issue 1, pp. 1-13.

[3]. Anil, A., Thampi, A.R., Prathap, J.M., \& Shanti, K.J., 2012 'An Automated Irrigation System for Home gardens', IEEE India Annual Conference (INDICON), Kochi, pp. 635-639..3.4, p. 109.

[4]. Zhang, M., \& Meng, Q., 2011 'Automatic citrus canker detection from leaf images captured in field', Elsevier, Pattern Recognition Letters, Vol. 32, Issue 15, pp. 2036-2046.

[5]. Rajkishore Prasad, Kumar Rajeev Rajan \& Sinha, A.K., 2006 'AMRAPALIKA: An Expert system for the diagnosis of pests, diseases, disorders in Indian Mango', Elsevier, Knowledge - Based Systems, Vol. 19, Issue 1, pp. 9-21. "PDCA12-70 data sheet," Opto Speed SA, Mezzovico, Switzerland.

[6]. Prakash, K., Saravanamoorthi, P., Sathishkumar, R., \& Parimala, M., 2017 'A Study of Image processing in Agriculture', International Journal of Advanced Networking and Applications, Vol. 09, Issue 01, pp. 3311-3315.J. Padhye, V. Firoiu, and D. Towsley, “A stochastic model of TCP Reno congestion avoidance and control," Univ. of Massachusetts, Amherst, MA, CMPSCI Tech. Rep. 99-02, 1999. 